\title{
Mastery Teachers: How to Build Success for Each Student in Today's Classrooms
}

\author{
Kym Acuña \\ Midwestern State University \\ Phillip J. Blacklock \\ Midwestern State University
}

The purpose of this mixed methods research study was to investigate the efficacy of master teachers $(n=60)$ and analyze the factors which support their success motivating and instructing P-12 students and effectively managing the classroom. The research design of this case study used an exploratory sequential mixed methods design (Creswell, 2015). The Teacher Self Efficacy Scale (TSES) (long form) sought to discover the capabilities teachers perceive having related to student engagement, instructional strategies, and classroom management (Tschannen-Moran \& Hoy, 2001). Participant teachers were interviewed through one-to-one conversation, to verify and enrich the findings (Bogdan \&; Biklen, 2007) produced by the TSES.

Our findings suggest master teachers are passionate about teaching; however, struggle at times with learners who have learning difficulties and off task behavior. Building relationships and developing social emotional skills is one of the most powerful tools for empowering students leading to their success. We also found efficacious teachers engage students in learning by relating to the real world, connecting to student interests, setting clear expectations, and establishing routines.

Keywords: teacher self-efficacy, classroom management, teacher education

\section{INTRODUCTION}

The purpose of this research project was to investigate the efficacy of in-service master teachers and analyze the factors which support their success in motivating and instructing P-12 students and successfully manage the classroom. Teacher efficacy is defined as the judgment of the teacher's capabilities to bring about desired outcomes of student engagement and learning (Tschannen-Moran \& Hoy, 2001). Through the Teacher Self Efficacy Scale (TSES) (long form) researchers can identify the capabilities teachers perceive relating to student engagement, instructional strategies, and classroom management (TschannenMoran \& Hoy, 2001).

Although a recent resurgence of teacher efficacy research has occurred (Nie, Lau, Liau, 2012), classroom management research is over 10 years old. Today's public school students learn much differently and participate in a society which is continually evolving (Daggett, 2014). Today's generation of students have a drastically different learning style and some of that is due to a shortened attention span. A survey done by Victoria Rideout (2012) demonstrated that $71 \%$ of teachers had seen a decrease in the attention 
span of their students due to the influence of the media. Creating engaging classrooms through active learning strategies and effective classroom management is essential for supporting the needs of both today's public school students and teachers.

Classroom management is the process by which a teacher creates a safe and positive classroom culture where students "sense a genuinely positively emotional climate" (Sousa, p. 9. 2021), thereby, motivating students to succeed and learn. The purpose of implementing classroom management strategies fostering social emotional growth while building positive teacher-student relationships (Sprenger, 2020) is to increase student academic motivation and heighten positive and appropriate social behavior (Emmer and Sabornie, 2015; Everston and Weinstein, 2006, Sousa, 2021, Sprenger, 2020). It is within this context we researched the efficacy of today's mastery teachers to understand how we can support their needs and empower our future teachers and education leaders.

\section{METHODS}

The research question which guided our research included: What classroom management strategies do mastery teachers use to successfully build positive and supportive classroom cultures.

The research design of this case study project used an exploratory sequential mixed methods design (Creswell, 2015). The mixed methods approach was described by Johnson and Onwuegbuzie (2004) as "a class of research where the researcher mixes or combines quantitative and qualitative research techniques, methods, approaches, concepts, or language in a single study" (p. 17). This approach allows the researcher to use both quantitative and qualitative measures to study the same set of questions, collect corresponding data and conduct parallel analyses (Yin, 2009) which adds depth and richness to the study.

This project used the Teachers' Sense of Efficacy Scale (TSES) Long Form developed by TschannenMoran and Woolfolk Hoy (2001). The scale utilized 24 items which were rated according to the following 1-9 ordinal scale: How much can you do? 1-Nothing, 3-Very Little, 5-Some Influence, 7-Quite A Bit, 9-A Great Deal. According to Tschannen-Moran ("Research Tools," n.d.) 24 item scale is used to measure the teacher's belief in their:

capability to make a difference in student learning, to be able to get through even to students who are difficult or unmotivated. The Teacher Sense of Efficacy Scale asks teachers to assess their capability concerning instructional strategies, student engagement, and classroom management. (II 3)

The items which align to efficacy in classroom management include:

3. How much can you do to control disruptive behavior in the classroom?

5. To what extent can you make your expectations clear about student behavior?

8. How well can you establish routines to keep activities running smoothly?

13. How much can you do to get children to follow classroom rules?

15 . How much can you do to calm a student who is disruptive or noisy?

16. How well can you establish a classroom management system with each group of students?

19. How well can you keep a few problem students from ruining an entire lesson?

21. How well can you respond to defiant students?

The scale was administered electronically through Survey Monkey and analyzed through the appropriate statistical analyses.

Reliability of the TSES data was analyzed using Cronbach's $\alpha$. Descriptive statistics (median, mode, quartile rank) and frequencies were used to derive meaning from the quantitative data collected from the TSES. Additional statistical analysis included chi square.

Participant teachers were interviewed through one-to-one conversation to verify the findings (Bogdan $\&$ Biklen, 2007) produced by the TSES. Interviewing added richness and rigor to the study by gathering descriptive data from the perspective of the participants so that insights can be developed concerning their school culture (Bogdan \& Biklen, 2007). The interview employed a semi-structured format (Merriam, 
1998) where a set of predetermined questions aligned to each of the key TSES dimensions were asked, yet there was flexibility within the interview protocol which allowed the researcher to "respond to the situation at hand, to the emerging world view of the respondent and to new ideas on the topic" (Merriam, 1998, p. 74).

The participant teacher face-to-face interviews consisted of 6 questions aligned to Efficacy in Student Engagement, Efficacy in Instructional Practices, and Efficacy in Classroom Management. The face-to-face interviews lasted 20-30 minutes and the following interview questions included but not limited to:

1. How do you get through to the most difficult students and keep them motivated even when the student does not show interest in schoolwork?

2. What are your most effective instructional practices for motivating students in today's classrooms? Elaborate.

3. What are your most effective assessment strategies for evaluating student learning needs in today's classrooms? Elaborate.

4. How do you establish an effective management system in your classroom supporting success for you and your students? What are the key components? Elaborate.

5. How do you respond to defiant students? In your opinion, what are the biggest factors influencing student attitudes?

6. What are your biggest challenges and how does this impact your capability to manage the classroom and provide engaging and effective instruction?

Upon completion of all the interviews, the data were coded and analyzed looking for emergent categories or themes (Seidman, 2006) that describe the status of Efficacy in Student Engagement, Efficacy in Instructional Practices, and Efficacy in Classroom Management and whether the interview information verified findings from the TSES. The analysis phase of the interview process included both coding and editing in paper copy (Seidman, 2006) to interpret the data. The members check strategy was used to make sure the interview findings were accurate and matched reality. The transcripts and tentative interpretations were sent back to each interviewed participant for corrections and additions.

The sample used in this study was selected through a convenience sampling method. The participants sample consisted of mastery teachers who were awarded the West Teaching Excellence Awards over the past five years. Over the last five years 114 elementary and secondary teachers have received the award.

\section{FINDINGS AND DISCUSSION}

Twenty-four teachers of the 114 award winners could not be located and were removed from the sample. Ninety teachers received the TSES survey, of which 60 chose to respond leading to a $67 \%$ response rate for teachers who received the survey.

The Cronbach $\alpha$ for the efficacy in classroom management data was 0.892 demonstrating a high level of reliability for this set of data. Each domain within the scale data demonstrated a high level of consistency ( $\alpha$ range of $0.88-0.90$ ).

Overall, the findings from the TSES data suggest master teachers feel confident in supporting the needs of their students, thereby, fostering their success (83\% reported 7-9 on the scale). Master teachers reported they can do a great deal to set clear expectations and establish routines for creating a positive classroom environment (Median/Mode $=9 / 9 ; 98 \%$ reported 7-9). Master teachers also felt confident in controlling disruptive behavior; encouraging students to follow classroom rules; and establishing a classroom management system for each group of students (Median/Mode $=8 / 9 ; 88 \%$ reported 7-9). Although master teachers felt confident overall, they showed to be slightly less confident in their ability to calm a student who is disruptive or noisy; keep a few students from ruining an entire lesson; and responding to defiant students (Median/Mode $=7 / 7 ; 69 \%$ reported 7-9). Percentiles were also lower for each of these areas (25: $6,50: 7,75: 8)$ as opposed to items aligned to more traditional aspects of classroom management, expectations, rules, routines $(25$ : 
Chi Square analysis indicated efficacy scores were significant for all classroom management items. However, the one sample Chi-Square Test found the distributions of category probabilities were not equally distributed within item scores.

While reviewing, coding, and categorizing interview data the following findings emerged:

- Master Teachers are passionate about connecting to the social emotional needs of students while building positive and supportive relationships.

- To engage students in learning, teachers must relate to the real world, connecting to student interests, thereby, fostering a learning environment responsive to the needs of each student.

- Positive and supportive expectations during active and engaging learning creates a positive culture for each student resulting in positive interactions and on task behavior.

- Master Teachers struggle at times with learners who have learning difficulties and off task behavior; however, building relationships and developing social emotional skills is one of the most powerful tools for empowering students leading to their success.

- Most defiant or off task behaviors relate to refusal to complete work.

These findings helped to enrich and verify what the master teachers reported on the TSES. Master teachers create a classroom environment where they build positive and supportive relationships with their students. This finding is supported by the strong evidence provided by the work of Hattie (2017) demonstrating the power of building positive relationships with students leading to improved learning by more than one year's growth. Although master teachers report to desire building positive relationships with their students, especially those who struggle, the lower efficacy scores in comparison to traditional classroom management strategies indicate room from growth and possible professional development aimed at improving how teachers create and sustain positive relationships with their students.

These teachers also effectively create a classroom management system which set positive expectations consistently implemented within the context of established routines and engaging lessons. Master teachers still struggle with defiant behaviors; however, overall believe in their ability to support the needs of each student who enters their classroom.

Future research would require a greater depth of investigation into differences found between master teachers, such as years of experience, grade level, and content area. Also comparing this data to teachers with varying years of experience including new and pre-service teachers can provide insight into how schools and educator preparation programs can provide professional development aimed at fostering healthy teacher-student relationships within a context of an engaged and supportive learning environment for all students.

\section{REFERENCES}

Bogdan, R., \& Biklen, S.K. (2007). Qualitative research for education: An introduction to theory and methods. Pearson Allyn \& Bacon.

Creswell, J.W. (2015). A concise introduction to mixed methods research. Sage Publications.

Daggett, W.R. (2014). The Daggett system for effective instruction: Where research and best practice meet. International Center for Leadership in Education.

Emmer, E.T., \& Sabornie, E.J. (Eds.). (2015). Handbook of classroom management (2nd ed.). Taylor and Francis Group.

Evertson, C.M., \& Weinstein, C.S. (Eds.). (2006). Handbook of classroom management. Taylor and Francis Group.

Glesne, C. (2006). Becoming qualitative researchers, an introduction (3rd ed.). Allyn and Bacon.

Hattie, J. (2017, December). Hattie's 2018 updated list of factors related to student achievement: 252 influences and effect sizes (Cohen's $d$ ). Retrieved from https://visible-learning.org/hattie-rankinginfluences-effect-sizes-learning-achievement/

Johnson, R.B., \& Onwueghuzie, A.J. (2004). Mixed methods research: A research paradigm whose time has come. Educational Researcher, 33, 14-26.

Merriam, S.B. (1998). Qualitative research and case study applications in education. Jossey-Bass. 
Nie, Y., Lau, S., \& Liau, A. (2012). The teacher efficacy scale: A reliability and validity study. The AsiaPacific Education Researcher, 21(2), 414-421.

Rideout, V. (2012). Children, teens, and entertainment Media: The view from the Classroom. Common Sense Media. Retrieved from https://www.commonsensemedia.org/research/children-teens-andentertainment-media-the-view-from-the-classroom

Seidman, I. (2006). Interviewing as qualitative research: A guide for researchers in education and the social sciences (3rd ed.). The Teachers College Press.

Sousa, D.A. (2021). Neuroscience research: Support for social-emotional learning and cognitive learning. Kappa Delta Pi Record, 57, 6-10. DOI: 10.1080/00228958.2021.1851580

Sprenger, M. (2020). Social emotional learning and the brain. ASCD.

Tschannen-Moran, M. (n.d.). Research tools. Retrieved from http://wmpeople.wm.edu/site/page/mxtsch/researchtools

Tschannen-Moran, M., \& Woolfolk Hoy, A. (2001). Teacher efficacy: Capturing and elusive construct. Teaching and Teacher Education, 17, 783-805.

Yin, R.K. (2009). Case study research: Designs and methods (4th ed.). Sage Publications Inc. 